\title{
Pembuatan Asap Cair Guna Mendukung Pertanian Organik di Desa Bulusari, Kecamatan Kalipuro, Kabupaten Banyuwangi
}

\author{
Sefri Ton ${ }^{1 *}$, Dwi Ahmad Priyadi ${ }^{1}$, Yeddid Yonatan Darma ${ }^{2}$ \\ ${ }^{1}$ Program Studi Teknologi Pengolahan Hasil Ternak, Politeknik Negeri Banyuwangi, Kabat, Banyuwangi, \\ Jawa Timur, Indonesia \\ ${ }^{2}$ Program Studi Teknik Manufaktur Kapal, Politeknik Negeri Banyuwangi
}

Submitted: 22 November 2019; Revised: 11 November 2020; Accepted: 12 November 2020

$\begin{array}{ll}\text { Kata Kunci: } & \text { Abstrak Bulusari merupakan desa yang terletak di Kecamatan Kalipuro. Wilayah } \\ \text { Asap cair } & \text { desa ini terdiri atas permukiman, lahan pertanian, dan perkebunan. Masyarakat } \\ \text { Desa bulusari } & \text { Desa Bulusari bermukim di tiga dusun, yaitu Bulupayung, Kopensere, dan } \\ \text { Limbah kayu } & \text { Plampang. Permukiman warga memiliki tipikal berupa rumah khas perkebunan. } \\ \text { Pestisida dan } & \text { Kopi dan sedikit cengkih banyak ditanam di sekeliling rumah warga. Lahan } \\ \text { pengawet } & \text { pertanian ditanami padi, ketela pohon, kelapa, dan buah-buahan. Di Desa Bulusari } \\ \text { makanan } & \text { juga terdapat usaha serkel kayu. Usaha serkel kayu tersebut menyisakan banyak } \\ & \text { limbah potongan kayu. Tujuan kegiatan ini adalah membantu masyarakat untuk } \\ & \text { memanfaatkan limbah kayu dan menghasilkan produk unggulan. Metode } \\ & \text { pelaksanaan kegiatan ini adalah introduksi inovasi pemanfaatan limbah kayu } \\ & \text { menjadi asap cair; mendesain dan membuat alat; praktik penggunaan alat; dan } \\ & \text { pengaplikasian penggunaan asap cair. Teknologi yang diterapkan mampu } \\ & \text { menghasilkan asap cair dengan grade } 3 \text { dan grade 2. Kegunaan asap cair ini adalah } \\ & \text { sebagai pestisida nabati/organik dan pengawet makanan. Pembuatan asap cair } \\ & \text { diharapkan dapat meningkatkan ketersediaan pestisida organik dan menciptakan } \\ & \text { lapangan pekerjaan baru bagi masyarakat Desa Bulusari. }\end{array}$

Keywords:

Liquid smoke

Bulusari village

Wood waste

Pestisides and

food

preservatives
Abstract Bulusari is a village located in Kalipuro District. This area consists of settlements, agricultural land and plantations. The villagers live in 3 hamlets, namely Bulupayung, Kopensere, and Plampang. The typical residential area here is a typical plantation house. The houses of the surrounding residents are planted with coffee and a few cloves. The agricultural land is planted with rice, cassava, coconut and fruit. Bulusari also has a wood serkel business. The wood serkel business leaves a lot of waste wood being wasted. The purpose of this activity is to assist the community in utilizing wood waste and producing superior products. The method of implementing this activity is the introduction of innovations in the form of utilizing wood waste into liquid smoke, designing and manufacturing tools, practice of using tools, application of using liquid smoke. The technology applied is able to produce liquid smoke with grade 3 and grade 2. The use of this liquid smoke is as a vegetable / organic pesticide, and food preservative. The production of liquid smoke is also expected to be able to provide organic pesticides and create new jobs for the people of Bulusari Village.

ISSN 2460-9447 (print), ISSN 2541-5883 (online)

${ }^{*}$ Corresponding author: Sefri Ton

Program Studi Teknologi Pengolahan Hasil Ternak, Politeknik Negeri Banyuwangi, alan Raya Jember No.KM13, Kawang, Labanasem, Kabat, Banyuwangi 68461, Jawa Timur, Indonesia

Email: sefriton@poliwangi.ac.id 


\section{PENDAHULUAN}

Banyuwangi adalah kabupaten yang memiliki julukan Sunrise of Java. Banyuwangi berbatasan langsung dengan Selat Bali. Luas wilayah Banyuwangi adalah $5.782,50 \mathrm{~km}^{2}$ yang terdiri atas lahan persawahan (66.152 ha) dan perkebunan (82.143,63 ha) (Badan Perencanaan Pembangunan Daerah, 2019). Banyuwangi juga merupakan daerah produksi perkebunan, pertanian hortikultura, dan tanaman pangan. Pertanian di Banyuwangi saat ini mulai menerapkan sistem pertanian modern dan organik. Produk pertanian berupa beras telah menembus pasar ekspor ke Italia, Australia, dan Amerika (Novalius, 2019). Banyuwangi juga menghasilkan buah naga organik dalam jumlah yang sangat melimpah.

Dalam sistem pertanian organik, pestisida organik/nabati tetap digunakan. Pestisida nabati merupakan bahan kimia aktif dari tumbuhan atau bahan organik lain yang digunakan sebagai pengendali hama pada tanaman. Pestisida ini dianggap aman bagi tanaman dan lingkungan (Sudarmo, 2005; Basri, 2010; Santoso, 2015; Sari et al., 2018). Pembuatan pestisida nabati juga mudah dan bahan yang diperlukan murah. Salah satu sumber pestisida nabati adalah asap cair.

Asap cair merupakan hasil pengembunan dari uap pembakaran bahan organik yang dilakukan secara langsung. Cairan hasil pembakaran tersebut mengandung berbagai senyawa yang dapat dipakai sebagai pestisida. Rosnawati (2016) mengatakan bahwa asap cair dapat digunakan sebagai pengendali hama. Selain itu, asap cair juga bisa digunakan sebagai pengawet ikan, daging, tahu, dan makanan lain dalam industri (Saparinto \& Hidayati, 2006; Fauzan \& Ikhwanus, 2017). Asap cair dibuat dengan bahan yang mengandung zat kayu (lignin), komponen struktur sel tanaman (selulosa dan hemiselulosa), dan senyawa arang (karbon) (Utomo et al., 2012). Komponen tersebut bersumber dari jenis kayu-kayuan, tempurung kelapa, sekam, serbuk kayu sisa gergaji, dan bahan lainnya. Bahan berupa potongan kayu hasil limbah serkel kayu dapat juga dimanfaatkan dalam pembuatan asap cair.

Usaha serkel kayu merupakan kegiatan memotong dan membelah kayu sesuai dengan ukuran yang dipesan oleh pelanggan. Di Desa Bulusari, Kecamatan Kalipuro, Kabupaten Banyuwangi, usaha serkel kayu dilakukan oleh mitra kegiatan ini, yaitu Moh. Badar dan Bapak Sukarto. Masalah yang muncul dari usaha ini adalah menumpuknya limbah kayu berupa sisa potongan dan serbuk kayu. Selain limbah kayu, limbah tempurung kelapa juga banyak dan mudah ditemukan di daerah ini karena Desa Bulusari merupakan daerah penghasil kelapa. Oleh karena itu, pemanfaatan hasil sampingan kayu dan tempurung kelapa menjadi asap cair yang mampu menghasilkan produk berupa asap cair (grade 1, grade 2, grade 3) dan arang aktif diharapkan dapat menjadi solusi permasalahan limbah tersebut.

Program penerapan teknologi pemanfaatan hasil sampingan/limbah kayu menjadi asap cair bertujuan sebagai berikut.

a. Memanfaatkan limbah kayu menjadi produk yang bernilai unggul, yaitu asap cair.

b. Menyediakan teknologi pembuatan asap cair di Desa Bulusari.

c. Menyediakan pestisida nabati bagi petani lokal dan bahan pengawet makanan dalam rangka mendukung program pemerintah daerah terkait dengan pertanian organik.

\section{METODE}

Metode pelaksanaan kegiatan ini adalah introduksi (sosialisasi) dan penyediaan teknologi serta praktek langsung pembuatan asap cair. Rangkaian kegiatan yang dilakukan adalah (a) berkomunikasi dengan mitra tentang pemanfaatan limbah kayu dari usaha serkel kayu; (b) berkoordinasi dengan pemerintah desa tentang sosialisasi dan diskusi kegiatan dengan masyarakat perihal teknologi yang ingin diterapkan; (c) mendesain dan membuat alat pembuatan asap cair yang sesuai dengan kondisi yang ada di masyarakat; (d) praktik penggunaan alat pembuatan asap cair; (e) pengaplikasian penggunaan asap cair yang dihasilkan; dan (f) pelaporan. Adapun data analisis yang dikumpulkan berupa pengujian kandungan asap cair yang telah dihasilkan.

Tahapan kegiatan sosialisasi kepada masyarakat bertujuan untuk memberikan informasi secara umum tentang program penerapan teknologi pemanfaatan limbah organik berupa limbah potongan kayu menjadi asap cair dan penggunaan asap cair dalam bidang pertanian. Tahapan ini juga bertujuan untuk mengetahui kebutuhan masyarakat desa yang umumnya bekerja sebagai petani. Tahapan selanjutnya adalah mendesain alat untuk pembuatan asap cair. Tahapan ini diharapkan tidak mengganggu aktivitas utama masyarakat. Desain juga diharapkan mudah dioperasikan dan mudah dirawat. Pada tahapan pengaplikasian asap cair dilakukan demostrasi penggunaan asap cair untuk pestisida dan penggunaan sebagai pengawet daging. Tahapan pengaplikasian tersebut melibatkan mitra dan masyarakat Desa Bulusari secara langsung.

\section{HASIL DAN PEMBAHASAN}

\subsection{Sosialisasi Program Pembuatan Asap Cair}

Sosialisasi program pembuatan asap cair pada perajin kayu dilakukan dengan melibatkan masyarakat desa, perajin kayu, serta dihadiri oleh Penanggung Jawab Desa Bulusari, Perangkat Desa Bulusari, dan 
panitia pengabdian. Tujuh puluh orang tercatat hadir dalam kegiatan ini. Adapun peserta yang hadir berasal dari kaum pemuda dan kelompok wanita tani di Desa Bulusari. Peserta yang hadir mengikuti acara sosialisai ini tampak antusias dan aktif sehingga terjadi komunikasi dua arah. Hal itu tampak ketika para pemuda desa dan ibu-ibu petani merespons materi penyuluhan yang disampaikan oleh tim dan mengajukan berbagai pertanyaan. Para pemuda desa yang hadir mengharapkan agar adanya alat destilasi asap cair akan memberikan peluang kerja baru bagi mereka. Kaum ibu-ibu petani di desa sangat tertarik dengan penggunaan asap cair sebagai pengawet makanan pengganti formalin.

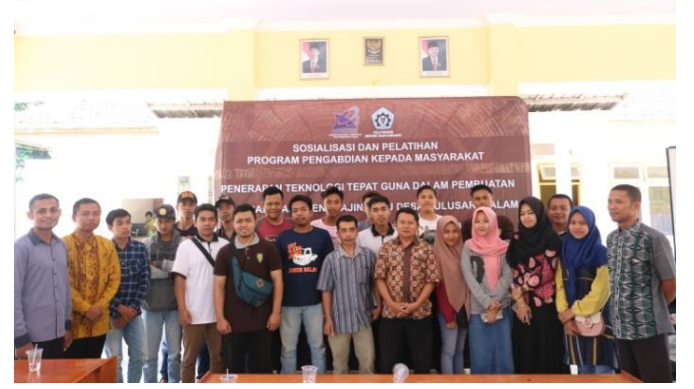

Gambar 1. Sosialisasi pemanfaatan limbah kayu dan penggunaan asap cair di desa Bulusari

\subsubsection{Pembuatan Alat Distilator 1 dan Hasil Asap Cair}

Pembuatan alat distilasi asap cair diawali dengan pembuatan desain alat, pembelian bahan, dan perakitan alat asap cair. Alat distilasi asap cair dibuat dengan teknik pembuatan arang aktif (metode terbuka) (Sumarno, 2014). Mekanisme kerja distilasi ini mengandalkan tekanan udara di sekitar alat. Langkah pertama yang dilakukan untuk menghasilkan asap cair adalah menyiapkan bahan baku berupa kayu, tempurung kelapa, atau limbah industri kayu. Kayu atau tempurung kelapa dimasukkan dalam tabung penampung bahan baku (No. 2 pada Gambar 2) sesuai kapasitas, yaitu $20 \mathrm{~kg}$. Bakaran/bara arang tempurung kemudian dituangkan secukupnya di posisi atas dari bahan baku untuk membakar bahan baku lain yang ada di dalam tabung. Tabung bahan baku selanjutnya diangkat hingga tersambung pada tabung pengatur udara (No. 4 pada Gambar 2).

Proses produksi asap cair berjalan dengan sendirinya. Bahan baku yang berada dalam tabung mulai terbakar. Bahan baku yang terbakar tersebut akan menghasilkan asap. Asap membuat tekanan meningkat pada reaktor (No. 7 pada Gambar 2). Saat tekanan meningkat, udara mengalir dari tabung pengatur udara menuju reaktor (No. 8 pada Gambar 2). Udara dari sekitar tungku dan ruang celah pipa (suhu rendah) secara perlahan bergerak meniup asap sehingga masuk ke pipa-pipa kondensor (No. 6 pada Gambar 2). Asap yang mengalir melalui pipa akan berubah menjadi cairan (konsep teori iklim) (Sumarno, 2014). Cairan yang menetes lewat pipa pembuangan (No. 5 pada Gambar 2) dan cairan asap dapat ditampung dengan wadah jeriken pada ujung saluran No. 9 pada Gambar 2. Proses pembuatan asap cair dengan metode terbuka ini berjalan selama enam jam dan cairan asap yang dihasilkan sebanyak 6-7 liter.

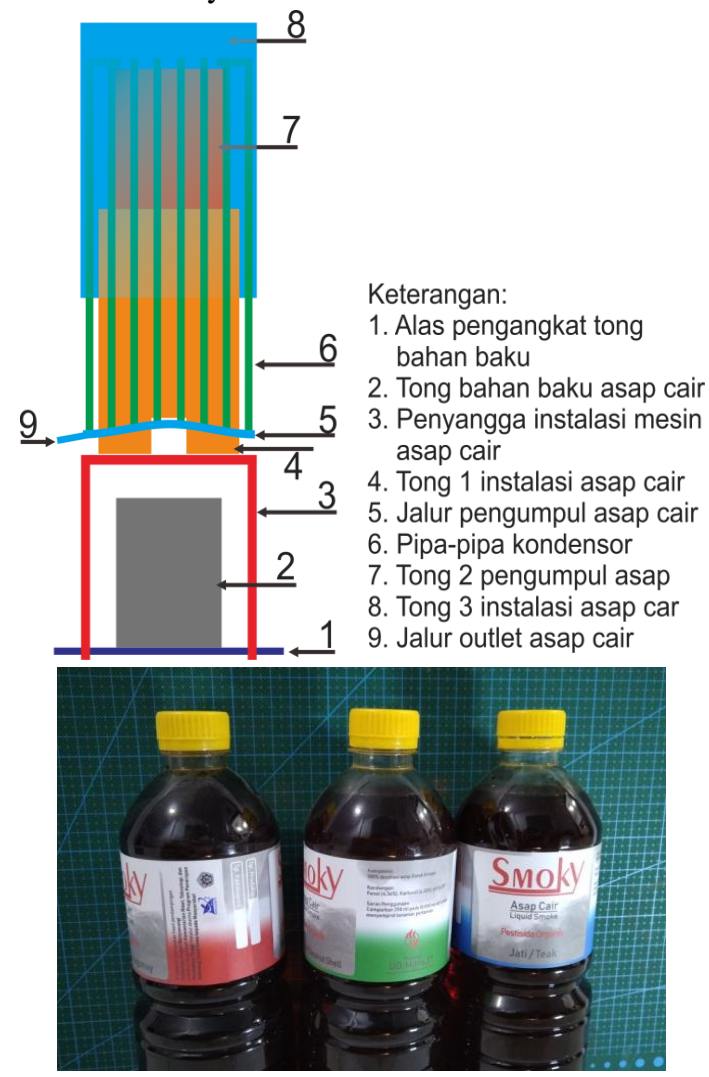

Gambar 2. Desain alat penghasil asap cair dan hasil cairan asap

Cairan asap yang dihasilkan dari proses ini berwarna hitam dan berbau tajam. Warna hitam disebabkan bahan berkarbon yang dihasilkan saat pembakaran. Cairan asap ini masuk dalam kategori grade 3 dan sudah dapat dijadikan pestisida. Adapun kandungan asap cair tersaji dalam Tabel 1.

Tabel 1. Hasil analisis laboratorium kandungan kimia asap cair distilasi 1 limbah potongan kayu

\begin{tabular}{|l|l|l|l|}
\hline Kandungan & \multicolumn{2}{|l|}{ Jenis Kayu } \\
\cline { 2 - 4 } $\begin{array}{l}\text { Kimia Asap } \\
\text { Cair (\%) }\end{array}$ & $\begin{array}{l}\text { Tempurung } \\
\text { Kelapa }\end{array}$ & Jati & Sengon \\
\hline $\begin{array}{l}\text { Total } \\
\text { Fenolik }\end{array}$ & 4,56 & 3,53 & 2,39 \\
\hline $\begin{array}{l}\text { Total } \\
\text { Karbonil }\end{array}$ & 6,30 & 6,70 & 5,83 \\
\hline pH & 4,07 & 4,10 & 3,90 \\
\hline
\end{tabular}

Total fenolik merupakan jumlah senyawa bahan alami yang ada dalam tumbuhan. Senyawa ini berfungsi untuk melindungi tanaman dari paparan sinar UV-B dan kematian sel. Komponen ini juga berperan sebagai agen pencegah dan pengobat dari serangan hama 
penyakit tanaman (Lai \& Lim, 2011). Senyawa fenolik juga berperan sebagai antioksidan pada tumbuhan. Hasil pengujian fenolik asap cair dari kayu menunjukkan bahwa kandungan terbaik terdapat pada tempurung kelapa, selanjutnya kayu jati dan sengon. Jumlah kandungan fenolik yang berbeda-beda dipengaruh oleh zat kayu (lignin). Kayu yang makin keras akan memiliki kandungan fenolik yang makin tinggi. Di dalam kandungan fenolik terdapat senyawa flavonoid (Hanin \& Rarastoeti, 2017). Flavonoid menjadi senyawa yang beracun bagi beberapa jenis serangga karena bersifat antivertilasi (Ispatrika, 2019). Penggunaan asap cair pada tanaman dapat mencegah serangga hama dan memberikan nutrisi tambahan bagi tanaman tersebut.

Proses pembakaran atau pemanasan selulosa dari kayu dengan panas $280-320^{\circ} \mathrm{C}$ dapat menghasilkan karbonil dan asam (Darmaji, 1996). Senyawa karbonil dapat disebut sebagai pemberi aroma (senyawa aromatik) dari asap cair. Adapun kandungan asam merupakan senyawa yang digunakan sebagai pengawet minuman/makanan dan racun bagi serangga. Senyawa asam tersebut merusak permeabilitas dari serangan hama. (Sari et al., 2018). Asap cair di bidang pertanian digunakan sebagai media efektif untuk mengusir serangga serta mempercepat pertumbuhan pada buah, bunga, daun, batang umbi, dan akar. Asap cair dalam kadar tertentu dapat membunuh hama tanaman dan meningkatkan kualitas tanah (Basri, 2010; Santoso, 2015). Penggunaan asap cair pada kayu mebel dapat menghambat kerusakan akibat rayap (Darmaji, 1996).

Asap cair yang akan digunakan dicampur dengan air terlebih dahulu, selanjutnya disemprotkan pada tanaman. Formula penggunaannya adalah $3 \mathrm{ml}$ asap cair dicampur dalam 1liter air. Formula asap cair tersebut mampu menghambat hama walang sangit (Leptocorisa oratorius) selama padi bunting sampai pascapanen. (Santoso, 2015). Pada program ini, masyarakat mengaplikasikan asap cair dengan melakukan demplot. Petani di desa ini melakukan penyemprotan asap cair pada tanaman padi dan cabai yang ditanam di lahan mereka. Tanaman cabai yang disemprot dengan asap cair tidak terkena hama, seperti thrips dan kutu daun. Selain itu, masyarakat mengaplikasikan asap cair untuk mengurangi bau dan mengusir lalat yang ada di kandang masyarakat. Asap cair sangat efektif digunakan karena tidak berbahaya bagi petani, tanaman, dan ternak.

\subsubsection{Alat Distilator 2 dan Hasil Asap Cair}

Alat distilasi 2 menggunakan metode penguapan gas karbon. Prinsip kerja distilasi 2 adalah bahan cair yang dipanaskan sampai titik didih akan menguap (Gambar 3). Hasil penguapan dapat dialirkan untuk ditampung. Senyawa karbon dan tar dalam asap cair dapat keluar dan hilang. Tahapan dalam proses distilasi ini adalah asap yang berada dalam tabung penampung asap (No 1 pada Gambar 3A) dipanaskan hingga menghasilkan uap. Uap tersebut mengalir melalui pipa distilasi yang dilewatkan dalam bak penampung air (No. 6 pada Gambar 3A). Media air akan mendinginkan uap dan uap akan berubah menjadi cair. Saat perubahan uap menjadi cair terjadilah pembuangan gas karbon.

Cairan asap hasil distilasi 2 berubah warna menjadi kuning ataupun putih dan bersih. Asap cair ini masuk dalam kategori grade 2 dan grade 1 . Ciri-ciri asap cair grade 2 adalah warna kuning pudar dengan aroma yang masih tidak begitu tajam apabila dibandingkan dengan asap cair grade 3 atau hasil distilasi 1. Adapun asap cair grade 1 berwarna bening, aroma tidak tajam, dan rasa sedikit asam. Asap cair ini tergolong food grade atau boleh digunakan untuk makanan (Salamah \& Jamilatun, 2017; Dewi et al., 2018). Kandungan asap cair distilasi 2 tersaji pada Tabel 2.

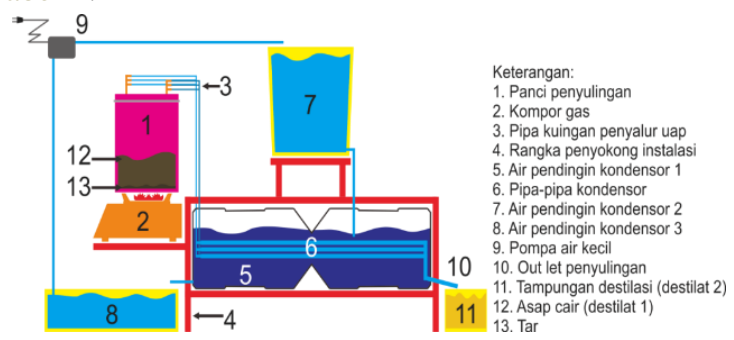

A
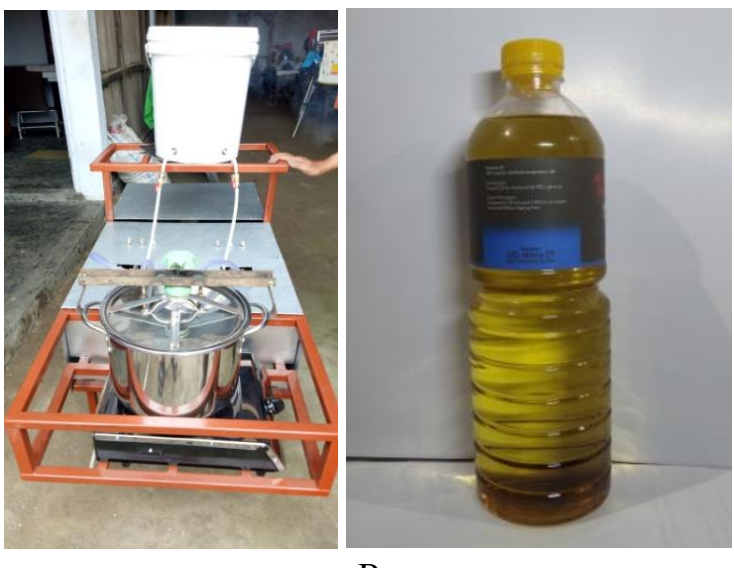

B

Gambar 3 A. Rancangan alat distilasi 2; B. Alat distilasi 2 yang dibangun dan hasil asap cair

Senyawa fenolik merupakan senyawa antioksidan dan antibakteri. Kandungan fenolik tertinggi pada asap cair terdapat pada tempurung kelapa $(1,86 \%)$, selanjutnya kayu jati $(1,14 \%)$ dan sengon $(0,54 \%)$. Penurunan nilai fenol asap cair hasil distilasi 2 terjadi karena alat ini menggunakan proses pemanasan lagi. Pemanasan yang lama dengan suhu yang tinggi dapat mengurangi kandungan fenolik asap cair (Andarwulan et al., 1996). Fenol merupakan golongan senyawa fitokimia yang banyak terdapat pada tumbuhan. Fenol telah terbukti mampu menghambat bakteri patogen, seperti Pseudomonas fluorescence, Bacillus subtilis, Ecoli, Staphylococcus aureus, Salmonella sp, dan 
Pseudomona sp. Pendapat ini juga didukung data hasil uji total bakteri. Asap cair dari tempurung kelapa memiliki total bakteri terendah (8 cfu/ml) (Tabel 2). Asap cair dapat digunakan untuk menggantikan formalin yang selama ini disalahgunakan oleh masyarakat. Asap cair juga telah banyak digunakan pada industri makanan sebagai preservatif dan pada industri farmasi (Darmaji, 1996; Sutin, 2008; Oktarina et al., 2017; Dewi et al., 2018).

Tabel 2. Hasil analisis laboratorium kandungan kimia asap cair distilasi 2 limbah potongan kayu

\begin{tabular}{|c|c|c|c|}
\hline \multirow{2}{*}{$\begin{array}{l}\text { Kandungan } \\
\text { Asap Cair }\end{array}$} & \multicolumn{3}{|c|}{ Jenis Limbah Kayu } \\
\hline & $\begin{array}{l}\text { Tempurung } \\
\text { Kelapa }\end{array}$ & $\begin{array}{l}\text { Kayu } \\
\text { Jati }\end{array}$ & Sengon \\
\hline Total fenolik & $1,86 \%$ & $\begin{array}{l}1,14 \\
\%\end{array}$ & $0,54 \%$ \\
\hline $\begin{array}{l}\text { Total } \\
\text { Karbonil }\end{array}$ & $5,23 \%$ & $\begin{array}{l}4,11 \\
\%\end{array}$ & $2,98 \%$ \\
\hline $\mathrm{pH}$ & 3,05 & 3,27 & 2,96 \\
\hline $\begin{array}{l}\text { Total } \\
\text { Bakteri }\end{array}$ & $8 \mathrm{cfu} / \mathrm{ml}$ & $\begin{array}{l}17 \\
\mathrm{cfu} / \mathrm{ml}\end{array}$ & $\begin{array}{l}46 \\
\mathrm{cfu} / \mathrm{ml}\end{array}$ \\
\hline
\end{tabular}

Dalam asap cair hasil distilasi 2, kandungan karbonil terbanyak berasal dari tempurung kelapa $(5,23 \%)$, selanjutnya kayu jati $(4,11 \%)$ dan kayu sengon $(2,98 \%)$. Senyawa karbonil ini dapat digunakan sebagai pemberi cita rasa dan warna pada produk asap cair. Kandungan $\mathrm{pH}$ dalam ketiga asap cair berbahan kayu dari distilasi 2 dapat dipakai sebagai pengawet. Asap cair memiliki nilai $\mathrm{pH}$ yang sesuai dengan standar mutu asap cair dari Jepang. Nilai $\mathrm{pH}$ yang sesuai dengan standar mutu asap cair dari Jepang adalah pada kisaran 1,50-3,70 (Yatagai, 2004). Asap cair yang memiliki $\mathrm{pH}$ rendah ini dapat menghambat pertumbuhan mikrob pada makanan, seperti ikan dan daging.

Beberapa kelebihan asap cair adalah mudah, praktis, dan produk memiliki flavor yang seragam. Asap cair lebih efisien digunakan sebagai bahan pengasap. Produk makanan yang menggunakan asap cair dinilai aman bagi kesehatan karena kandungan senyawa Polycyclic Aromatic Hydrocarbon (PAH) lebih rendah. Senyawa PAH merupakan senyawa karsinogenik (yang beracun) yang umumnya terdapat pada produk bersuhu tinggi, khususnya produk ikan asap dan daging asap (Ghazali et al., 2014). Pengaplikasian asap cair dalam bahan makanan dilakukan dengan mengawetkan daging sapi segar. Daging sapi yang dicelupkan dalam asap cair selama \pm 25-30 akan tetap layak untuk dikonsumsi pada hari ketiga. Cita rasa daging sapi tersebut juga sangat khas asap cair.

\subsubsection{Penerapan Penggunaan dan Serah Terima Alat kepada Masyarakat}

Kegiatan penerapan penggunaan teknologi dilakukan dengan pelatihan penggunaan alat distilasi dan penggunaan asap cair pada produk daging sebagai pengawet. Kegiatan penerapan dilaksanakan pada 4 November 2019 dan dihadiri 60 peserta yang merupakan warga Desa Bulusari. Peserta berasal dari tokoh masyarakat, RT/RW, kelompok wanita tani, karang taruna, masyarakat kurang mampu, penanggung jawab desa, kepala desa terpilih 2019, serta Perangkat Desa Bulusari. Peserta yang hadir antusias untuk mengikuti kegiatan pelatihan penggunaan alat dan penggunaan asap cair pada daging. Masyarakat sangat menyukai teknologi pembuatan asap cair dengan metode ini karena pengoperasian alat distilasi 1 tidak menghalangi aktivitas utama ketika sedang bekerja.

Alat distilasi 1 dapat berfungsi sendiri ketika digunakan sehingga tidak harus dijaga. Aktivitas alat ini berlangsung selama 6-7 jam untuk menghabiskan semua bahan baku limbah kayu menjadi asap cair. Alat ini juga tidak menimbulkan polusi atau meninggalkan limbah lagi. Semua hasil aktivitas pembuatan asap cair dapat dimanfaatkan. Hasil asap cair grade 3 dapat langsung disemprotkan pada tanaman. Pengoperasian alat distilasi 2 sangat mudah, yaitu dengan memanaskan asap cair hasil distilasi 1 yang secara otomatis akan menghasilkan asap cair grade 2 dan grade 1.

Kegiatan penerapan teknologi tepat guna bagi masyarakat Desa Bulusari diakhiri dengan serah terima alat yang dilakukan oleh Ketua Pusat Penelitian dan Pengabdian Masyarakat Politeknik Negeri Banyuwangi, mitra (perajin/serkel kayu), ketua tim pelaksana pengabdian, dan Penanggung Jawab Desa Bulusari serta disaksikan oleh semua hadirin. Masyarakat dan kepala desa terpilih menilai pemanfaatan teknologi tepat guna di Desa Bulusari ini sangat tepat karena Desa Bulusari merupakan daerah penghasil kayu, kelapa, dan berbagai hasil hutan lainnya. Pada umumnya, kayu hasil limbah industri perajin kayu dijual murah kepada perajin tahu, pembakar batu bata, atau dibakar habis. Bahan baku asap cair yang lain yang juga melimpah di Desa Bulusari adalah tempurung kelapa, kulit durian, dan kopi.

Kualitas asap cair dapat dimurnikan lagi untuk tujuan industri makanan. Pembuatan asap cair juga dapat menciptakan pekerjaan baru bagi masyarakat Desa Bulusari. Salah satu pemuda Bulusari mengatakan bahwa teknologi ini bisa mencegah mereka keluar dari kampung untuk mencari pekerjaan di kota. Mengoperasikan alat distilasi tidak menghalangi aktivitas utama ketika sedang bekerja. Alat ini dapat berfungsi sendiri ketika digunakan sehingga tidak harus dijaga. Aktivitas alat ini berjalan selama 6-7 jam 
untuk menghabiskan semua bahan baku. Setelah 6-7 jam, proses pembakaran selanjutnya dapat dilakukan.

Cairan asap yang dihasilkan di Desa Bulusari dengan distilasi 1 (asap cair grade 3) dijadikan pestisida nabati. Harga jual produk ini sekitar Rp20.000- sampai Rp30.000,- untuk kemasan 1 liter (Gambar 2 dan Gambar 3). Produk asap cair bisa dijual kepada petani sebagai bahan baku pestisida organik dan dapat digunakan oleh perajin kayu/mebel sebagai pengawet kayu. Asap cair distilasi 2 (asap cair grade 1 dan grade 2) dapat dijual kepada pihak industri makanan dan farmasi. Kegiatan selanjutnya adalah pendampingan dalam memasarkan produk asap cair kepada petani lain. Pendampingan tersebut bertujuan untuk memastikan produksi asap cair terus berjalan sehingga masyarakat mendapatkan manfaat yang nyata.

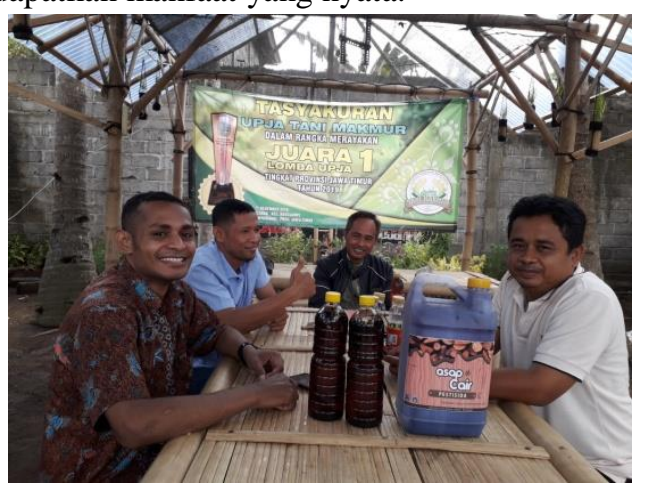

Gambar 4. Komunikasi dengan kelompok UPJA Tani Makmur di Desa Gladag, Banyuwangi dalam pemasaran produk asap cair

\section{KESIMPULAN}

Penerapan teknologi tepat guna pembuatan asap cair pada perajin kayu di Desa Bulusari bertujuan untuk memanfaatkan limbah kayu agar menghasilkan produk asap cair yang dapat dijual kepada petani dan industri makanan. Teknologi yang dihasilkan berupa alat distilasi asap cair yang dibagi menjadi dua bagian, yaitu distilator 1 asap cair dengan metode pembuatan arang agar menghasilkan asap cair kategori grade 3. Asap cair ini dapat digunakan untuk pestisida organik. Adapun alat distilator 2 mampu menghasilkan asap cair grade 2 dan grade 1 yang digunakan untuk pengawet makanan. Teknologi distilasi asap cair ini dapat menambah pendapatan masyarakat dan memberikan lapangan pekerjaan baru bagi masyarakat Desa Bulusari.

\section{UCAPAN TERIMA KASIH}

Program pengabdian masyarakat ini dapat terlaksana berkat dukungan dana dari Kementerian Riset, Teknologi, dan Pendidikan Tinggi melalui skema Penerapan Program Teknologi Tepat Guna kepada Masyarakat (PPTG) dengan kontrak No. 184/SP2H/PPM/DRPM/2019.

\section{REFERENSI}

Andarwulan, N., Wijaya, H., \& Cahyono, D.T. (1996). Aktivitas Antioksidan dari Daun Sirih (Piper betle L). Buletin Teknologi dan Industri Pangan, 7(1), 29-30.

Badan Perencanaan Pembangunan Daerah. (2019). Sosialisasi Kegiatan Penelitian dan Pengabdian Ilmu Pengetahuan dan Teknologi Tahun 2019. Badan Perencanaan Pembangunan Daerah Kabupaten Banyuwangi, Jawa Timur.

Basri, A.B. (2010). Manafaat Asap Cair untuk Tanaman. Seri Inovasi Pembangunan Serambi Pertanian, 4(5), 1-2.

Darmadji. (1996). Antibakteri Asap Cair dari Limbah Pertanian. Agritech, 16(4), 19-22.

Dewi, J., Gani, A., \& Nazar, M. (2018). Analisis Kualitas Asap Cair Tempurung Kelapa dan Ampas Tebu sebagai Bahan Pengawet Alami pada Tahu. Jurnal IPA dan Pembelajaran IPA, 2(2), 106-112.

Fauzan \& Ikhwanus, M. (2017). Pemurnian Asap Cair Tempurung Kelapa Melalui Distilasi dan Filtrasi Menggunakan Zeolit dan Arang Aktif. Seminar Nasional Sains dan Teknologi 2017.

Ghazali, R.R., Swastawati, F., \& Romadhon. (2014). Analisa Tingkat Keamanan Ikan Manyung (Arius thalassinus) Asap yang Diolah dengan Metode Pengasapan Berbeda. Jurnal Pengolahan dan Bioteknologi Hasil Perikanan, 3(4), 31-38.

Hanin, N.N.F. \& Rarastoeti P. (2017). Kandungan Fenolik, Flavonoid, dan Aktivitas Antioksidan Ekstrak Daun Paku Laut (Acrostichum aureum L.) Fertil dan Steril. Journal of Tropical Biodiversity and Biotechnology, 2, 51-56.

Ispatrika A. (2019). Pembuatan Pestisida Nabati sebagai teknologi Ramah Lingkungan. Balai Penelitian Lingkungan Pertanian Kementerian Pertanian, Jakenan.

Lai, H. \& Lim, Y. (2011). Evaluation of antioxidant activities of the methanolic extracts of selected ferns in Malaysia. International Journal of Environmental Science and Development, 2(6), $442-447$.

Novalius F. (2019). RI Ekspor Beras Organik Banyuwangi ke Italia hingga Amerika. https://economy.okezone.com/read/

Oktarina, D., Sumpono, \& Elvia, R. (2017). Uji Efektivitas Asap Cair Cangkang Buah Hevea braziliensis terhadap Aktivitas Bakteri Es. Jurnal Pendidikan dan Ilmu Kimia, 1(1), 1-5.

Rosnawati, T. (2016). Pemanfaatan Limbah Kulit Durian sebagai Bahan Baku Briket dan Pestisida Nabati. Jurnal: Biology Sciece And Education, 5(2), 159-170.

Salamah \& Jamilatun, (2017). Pemanfaatan Asap Cair Food Gradeyang Dimurnikan dengan Arang Aktif sebagai Pengawet Ikan Nila. Eksergi, 14(2), 29-34.

Santoso, R.S. (2015). Asap Cair Sabut Kelapa sebagai Repelan Bagi Hama Padi Walang Sangit (Leptocorisa oratorius). Jurnal Sainsmat, 4(2), $81-86$. 
Sari, Y.P., Samharinto, \& Langai, B.F. (2018). Penggunaan Asap Cair Tandan Kosong Kelapa Sawit (TKKS) sebagai Pestisida Nabati untuk Mengendalikan Hama Perusak Daun Tanaman Sawi (Brassica juncea L.). EnviroScienteae, 14(3), 272-284.

Saparinto, C. \& Hidayati, D. (2006). Bahan Tambahan Pangan. Yogyakarta: Kanisius.

Sudarmo, S. (2005). Pestisida Nabati. Yogyakarta: Kanisius.

Sumarno. (2014). Teknologi Pengubah Tempurung Kelapa Menjadi Cairan Asap (Asap Cair). Fakultas Pertanian Universitas Abdulrahman Saleh, Situbondo.

Sutin. (2008). Pembuatan Asap Cair dari Tempurung Kelapa dan Sabut Kelapa Secara Pirolisis serta Fraksinasinya dengan Ekstraksi [Skripsi tidak dipublikasikan]. Institut Pertanian Bogor, Bogor.

Utomo, B.S.B., Wibowo, S., \& Widianto, T.N. (2012). Asap Cair: Cara Membuat dan Aplikasinya pada Ikan Asap. Jakarta: Penebar Swadaya.

Yatagai, M. (2004). Utilization of Charcoal and Wood Vinegar in Japan. Graduate School of Agricultural and Life Sciences. The University of Tokyo, Tokyo. 